Gazi University
Journal of Science
http://dergipark.gov.tr/gujs

\title{
Efficiency Analysis of Synthetic Methane Production in Power-to-Gas Process Employing Solid Oxide Electrolyser
}

\author{
Irfan Ahmad GONDAL* \\ National University of Technology (NUTECH), Islamabad, Pakistan
}

\author{
Highlights \\ - Heat recovery in Sabatier process improves efficiency of the process. \\ - Recovered heat is used to heat feed water at inlet of Solid oxide electrolyser \\ - Compression prior to methanation gives best efficiency and quality of methane.
}

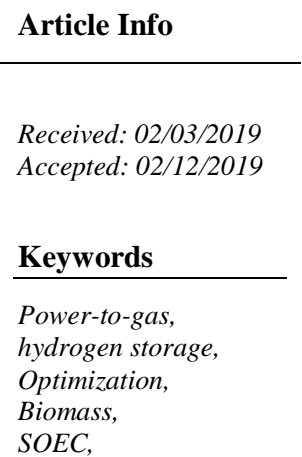

\begin{abstract}
The power-to-gas technology is considered to provide the means of storing surplus renewable energy in the form of synthetic natural gas. The study analyses the P2G system with respect to the three main components i.e. electrolysers (especially solid oxide electrolysers that have a higher operating temperature), the methanation reactor and the synthetic methane injection system. Efficiency of the individual components is evaluated with three different configurations employing heat recovery at various sections of the P2G system. The model has been studied in the ANSYS environment. The configurations are finally evaluated for an optimized solution as regards the efficiency of the entire system and the quality of the produced synthetic.
\end{abstract}

\section{INTRODUCTION}

Hydrogen is a strong future candidate as a substitute for the hydrocarbon based fuels. In the absence of fossil fuels, the alternative energy resources based on renewables are able to generate green power by running the electrolysers that can subsequently produce hydrogen. The stochastic nature of the renewable energy technologies (RET) especially solar and wind is posing challenges for the existing electricity distribution networks. Moreover the intermittent nature of RETs raises technical issues in terms of voltage stability, power quality and reliability. It thus becomes imperative that large grid-scale storage be studied to enable full potential of the renewable energy resources. Power-to-gas (P2G) system is conceived to fulfill the need for storing mass-scale energy generated by Renewables in existing natural gas (NG) distribution networks. Further, in view of the climate change phenomena and associated environmental effects, hydrogen, from some recent past, is being advocated as the future fuel. Hydrogen economy, if it has to realize, requires the production of hydrogen in enormous amounts comparable to the current availability and consumption of fossil fuels. In this regard renewable resources are being viewed as an important participant in the initiation and development of hydrogen economy world-wide [1]. The solar and wind energy provide the power to run the electrolysers for generating pure hydrogen and oxygen.

Steam methane reformation when carried out in the reverse order results in the formation of SNG. The reaction is a well-known chemical process denoted by the succeeding equations given below and known as the Sabatier reaction:

$\mathrm{CO}+3 \mathrm{H}_{2} \leftrightarrow \mathrm{CH}_{4}+\mathrm{H}_{2} \mathrm{O}$

$\mathrm{CO}_{2}+4 \mathrm{H}_{2} \leftrightarrow \mathrm{CH}_{4}+2 \mathrm{H}_{2} \mathrm{O}$ 
The two oxides of carbon namely carbon monoxide and carbon dioxide when reacted and heated with hydrogen gas in the presence of a catalytic agent results in the formation of synthetic methane. The process flow of methanation as represented by chemical reaction (2) is shown in Figure 1 [2].

Figure 1 shows two reactors for the generation of methane. First reactor receives hydrogen and $\mathrm{CO}_{2}$ in the ratio 4:1 resulting in methane and water with some traces of reactants. The second stage increases the methane fraction. Based on Hashimoto's [3] findings if each of these reactors has an efficiency of $90 \%$, the overall conversion efficiency enhances to $99 \%$. Gao et al [4] has evaluated various studies which indicate that catalysts under development would be able to achieve this conversion efficiency in the near term.

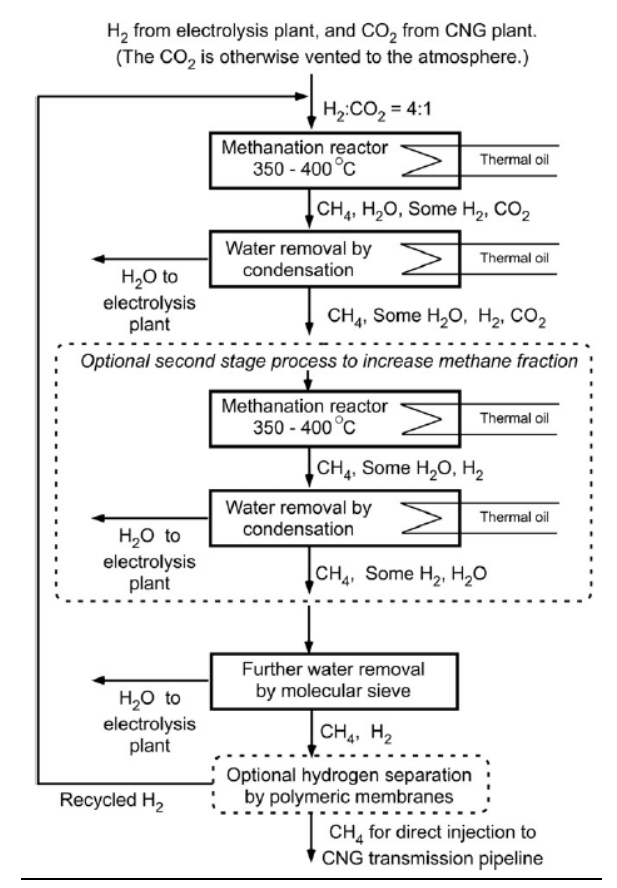

Figure 1. SNG Process flow [2]

The P2G concept is considered to provide a solution to the long standing problem of storing the surplus renewable energy obtained through the solar and wind resources. In a hydrogen economy, the P2G technology also solves the issue of the transportation of hydrogen in the transmission and distribution networks [5, 6]. Maroufmashat and Fowler [7] have concluded that a P2G system centered on renewable energy generation is an innovative concept. The study suggests that with such a system it is possible to evolve a future low-carbon energy system that is based on an increased content of renewable energy. To facilitate the transition, a number of strategies have been devised. Gondal [8] has discussed the integration of hydrogen in the P2G networks both in the Distribution as well as the Transmission networks. The significance of $\mathrm{P} 2 \mathrm{G}$ systems in relation to the renewable energies is seen to be expanding with more approaches being included to accommodate the growing output from various renewable energy resources. Offshore energy resources particularly offshore wind has been linked with P2G systems in a latest study [9]. This study highlights how P2G systems are able to generate SNG in an offshore island with the help of Carbon capture and utilization. In a similar study [10], it has been found that P2G along with offshore renewable energy and oil exploration companies have the potential to address the climate change issues as well. In this regard, the methanation process that is at the heart of $\mathrm{P} 2 \mathrm{G}$ systems needs to be analysed for achieving higher efficiencies.

\subsection{Elements of P2G System:}

The P2G system comprises of three significant elements along with other minor accessories and components. These are:

\section{- The electrolysers}


Several electrolysers are available for commercial scale generation of hydrogen. Solid Oxide electrolysers (SOE) and Proton Exchange Membrane (PEM) are also being developed in addition to the conventional Alkaline electrolysers. SOE are more efficient; however these electrolysers operate at higher temperatures and are studied in the current work.

\section{- Methanation reactor}

Synthetic methane production by the Sabatier process is an established technology [11]. Feedstock for methanation is in the form of biomass, besides Carbon is also available in the form of flue gases in NG resource fields. Emissions from industries are another source of carbon along with waste heat [12].

\section{- Synthetic methane Injection system (SMIS)}

This system primarily consists of compressors and may involve one or more compression stages. Compressors for methane (NG) are also a commercially established technology. Nevertheless, in order to improve the all-inclusive efficiency of the $\mathrm{P} 2 \mathrm{G}$ system it is imperative that the efficiency of the individual components be also evaluated in detail.

P2G process has the potential to resolve many technical and economic issues associated with future energy provision particularly when renewable energy resources are being looked upon as the major contributor of energy supplies. The efficiency of $\mathrm{P} 2 \mathrm{G}$ systems is hence a topic of great interest among the energy planners and researchers.

\section{P2G - ADVANCES IN EFFICIENCY}

P2G technology is being considered to have the linchpin status in the future energy system and hence the efficiency of the complete process needs to be analyzed. The key elements of the $\mathrm{P} 2 \mathrm{G}$ process include the electrolysers, the methanation plant and the injection systems. The overall efficiency of the entire P2G process is dictated by the individual efficiencies of these $\mathrm{P} 2 \mathrm{G}$ elements. Several studies have discussed the P2G systems targeting various aspects of the process; most of these studies assess the techno-economic aspects while others focus on individual elements.

In context of electrolysers in the current scenario, alkaline electrolysers (AEL) are considered as the cheapest and most reliable technology [13]. AEL are particularly suited for P2G systems because of their ability to operate at varying loads. AELs are able to operate at $20-100 \%$ of the design capacity, and can be overloaded for up to $150 \%$ which makes it a good candidate for coupling with RETs [14]. RETs have a characteristic fluctuating and intermittent power supply that suits the wide capacity range of AELs. In transient operation PEM electrolysis has seemingly better performance. It is however a comparatively expensive technology, has a faster cold start and suitable for intermittent operations. The purity of hydrogen is very high but is associated with a shorter lifecycle of the equipment [15]. Solid oxide electrolysers (SOE), also known as high temperature electrolysers are the newest category of electrolyzers and currently being evaluated on a laboratory scale only. In SOEs the electrolyte consists of $\mathrm{ZrO}_{2}$ doped with $8 \mathrm{~mol} \% \mathrm{Y}_{2} \mathrm{O}_{3}$, resulting in a material highly conductive for oxygen ions. The SOEs are thermally and chemically very stable [16]. The low electricity demands and theoretically higher than $100 \%$ electrical efficiencies is the most significant advantages of SOEs. The P2G processes have exothermal reactions and hence the use of SOEs in these processes results in higher overall efficiencies $[17,18]$.

The methanation process has been reviewed in the literature previously in terms of a comparison of catalytic and biological methanation. Other studies basing on reactors compare the working of the fluidized-bed and the fixed bed. Gotz et al [19] have made a comprehensive review of the methanation process chain. Similarly Sebastian et al [20] have made a technological review of the P2G process. In this study the P2G paths are analysed in terms of the process chains. Several transformation technologies have also been evaluated for their conformation to different applications. It also gives a comprehensive account of the various choices available for storing and distribution of $\mathrm{CO}_{2}$ alongwith the end-user applications. 
A limited amount of literature is found on the configuration of the $\mathrm{P} 2 \mathrm{G}$ process elements as regards the various operating parameters. Bensmann et al [21] have evaluated the optimal pressure levels of the P2G process. In this study the sequence of mechanical compressor and dryer is evaluated to determine the best pressure profile. The methanation step is the decisive process that determines the overall efficiency of the P2G process. Frontera et al [22] have discussed the efficiency of the methanation process in terms of the various catalysts. In this study the noble metal and nickel based catalysts are analysed in comparison with bio-methanation. Parra and Patel [23] have discussed the electrolysers in techno-economic terms and their size for P2G systems. Martin et al [24] have presented the technical and economic assessment of the german project "Energiepark Mainz". This technical assessment is based on the total energy consumption of the electrolysers alongwith the energy utilization factor. On the other hand the economic analysis discusses the electricity procurement choices available to run the electrolysers . In two other studies $[25,26]$ the powerto gas system is studied in context of cost optimization model and determining the economic optimum of the PtG capacity respectively.

The technical aspects of the $\mathrm{P} 2 \mathrm{G}$ process that deal with the operation of the electrolysers, methanation plant or the injection system have been found to be unfrequented in the published literature. Bailera et al [27] has proposed the combination of a methanation plant and an oxycombustion coal boiler to improve the efficiency of the P2G process. The same author in another study [28] has suggested hybridization in terms of oxy-combustion of biomass that can enhance the deployment of Power to Gas technology. Gillessen et al [29] has proposed the hybridization of P2G with battery storage however the same has been found to be economically uncompetitive. Kezibri and Bouallou [30] have suggested oxy-combustion and it has been demonstrated that $155 \mathrm{MW}$ of SNG has been produced from a thermally integrated Sabatier process with an input of 200MW of electric supply to the electrolysers. The study further adds that if enough amounts of SNG and oxygen is produced and stored, another $480 \mathrm{MW}$ can also be recovered with the use of an oxycombustion power plant. Yet another study [31] on hybridization of P2G suggests utilizing the flue gas of an oxyfuel boiler as the source of $\mathrm{CO}_{2}$ for the methanation process.

The novelty of the present work in this regard is that it addresses the efficiency of the complete P2G by considering the position of the electrolysers, compressors and the methanation plant in different configurations. In this regard the Solid Oxide Electrolyser (SOE) technology is evaluated as part of the P2G network.

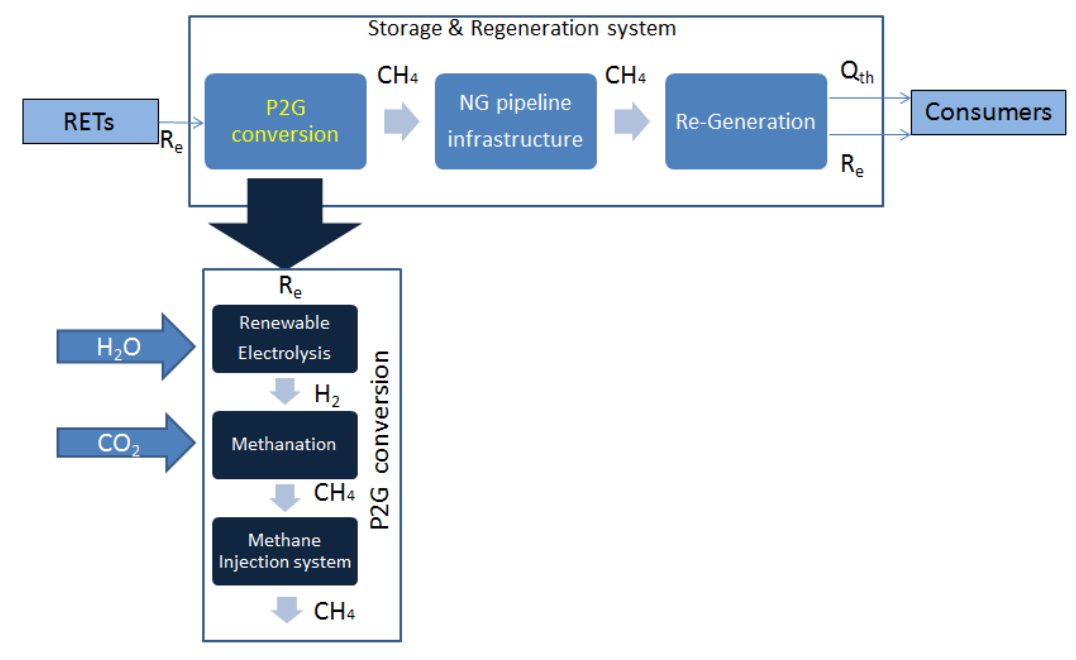

Figure 2. P2G storage system

The P2G system uses the electricity generated from RETs (PV \& Wind energy) and conversion into methane takes place according to the Sabatier reaction. Figure 2 schematically shows the complete process from the generation of initial electrical power from RETs to the final consumer. The focus of this analysis would be the $\mathrm{P} 2 \mathrm{G}$ conversion system with respect to the three main elements already discussed in the preceding writing. 


\section{MATERIALS AND METHODS}

The P2G storage system is modeled in ANSYS, a software that simulates the engineering problems by using finite element analysis. This software is capable of designing products, and can test its durability. It can also carry out simulation for testing the product's electromagnetic properties, the distribution of temperature within a product's body as well as the fluid movements. Considering the renewable energy systems there are many applications where ANSYS is being used. ANSYS has enabled many R\&D organizations in the development of innovative equipment and in enhancing the reliability and working of the existing systems. For instance, instead of the development of expensive physical prototypes, ANSYS reduces the lead time by simulating the design and operation of various renewable energy devices including fuel cell stack, PV collectors and biomass reactors etc. In case of Wind Energy as well, ANSYS is able to solve complex mathematical equations pertaining to fluid mechanics, structural mechanics, vibration analysis etc concerned with the operation and working of a wind turbine. Similarly the critically important Wind Turbine control systems also fall in the domain of this software.

ANSYS has consistently been used by researchers for investigation of building energy problems. Rajakumar [32] has drawn a comparison of energy use in concrete buildings with and without insulation using ANSYS. Elghazi et al [33] has modeled and integrated solar shading in hot climates with double skin facades using ANSYS. Similarly Nejat et al [34] has used wind catchers as a means of passive cooling and modeled it with the help of ANSYS. In another study ANSYS has been employed to investigate the ventilation in building-integrated photovoltaic system [35]. The P2G model under study has been analyzed with a number of configurations to ascertain two main parameters for achieving optimization i.e. firstly the efficiency of energy conversion and secondly the yield in terms of synthetic methane production. The configurations have been designed to allow for the use of waste heat through a heat exchanger setup. Similarly the compression stages have been re-positioned to analyze the behavior of the complete P2G conversion system.

\subsection{MODEL DEVELOPMENT}

The Reference case depicted in Figure 3 shows three distinctive steps i.e. the solid oxide electrolyzer cell (SOEC), Methanation reactor and the SMIS. In the reference configuration the SOEC requires a heated input of water stream for achieving higher efficiency which is accomplished through an external source. After the electrolysis, the hydrogen stream is separated from the oxygen stream through a sweep stream and then both the streams are cooled down to the ambient temperature $\left(27^{\circ} \mathrm{C}\right)$. SEP1 and SEP2 represent two separators are shown in the reference configuration with the following function:

- SEP1-After condensation, $\mathrm{H}_{2}$ stream is cooled down by elimination of water.

- SEP2-Separation of methane from water after the Sabatier reaction.

After removal of water the methane stream is passed through the SMIS which includes the intercooler and after-cooler for attaining the requisite pressure of the NG pipeline network. Referring to Figure 3, HXI represents a heat exchanger used to pre-heat the incoming stream of feed water. $C 1 / C 2 / C 3$ are condensers and are used for removal of heat as indicated with an outward flow of heat i.e. $Q 2 / Q 3 / Q 4$. Syn $/ / S y n 2 / S y n 3$ is used to denote SNG moving downstream of Sabatier reactor. COMP represents compressor/compression stages in the succeeding figures. Cathode and Anode streams are the outflows from the respective electrodes of the solid-oxide electrolyser cell. Table 1 represents the data for Reference case. 


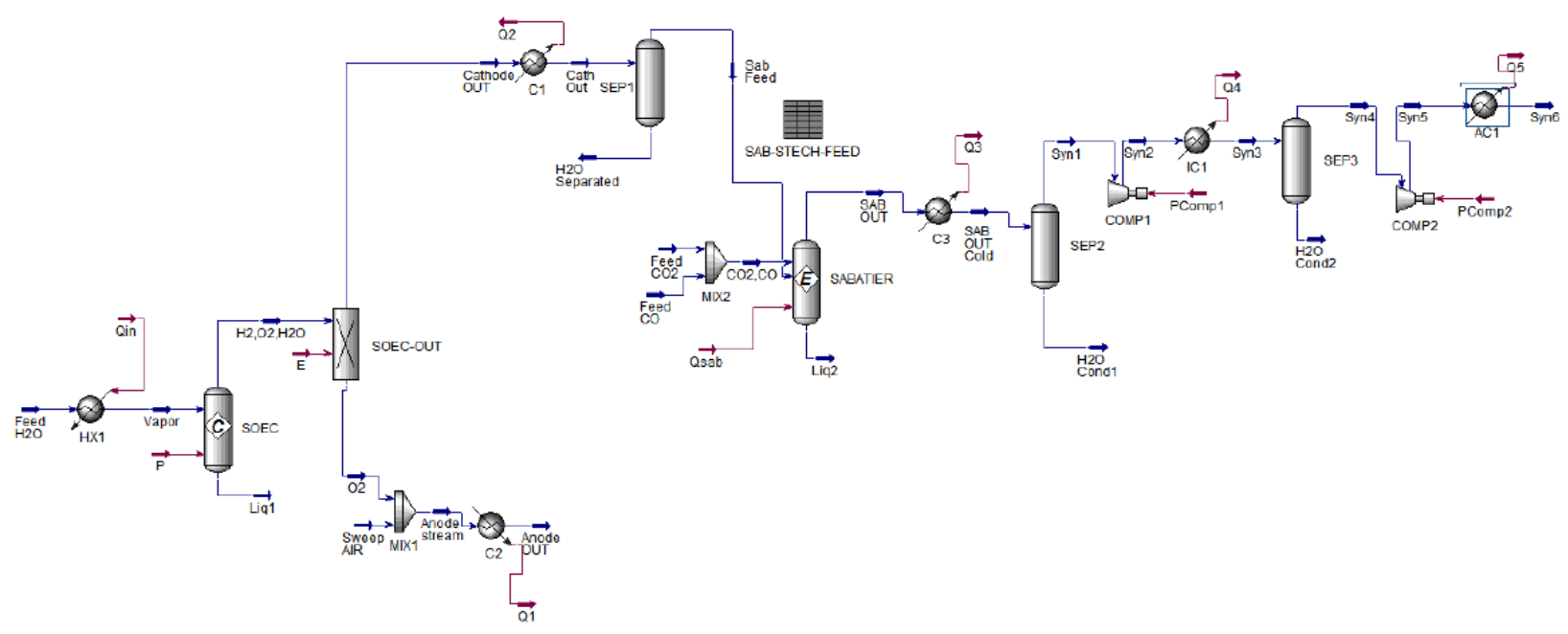

Figure 3. Reference case

Table 1. Operating parameters for $P 2 G$ storage system

\begin{tabular}{|l|l|}
\hline Parameter & Values \\
\hline SOEC & $1 \mathrm{MW}$ \\
\hline Input electric power & $850^{\circ} \mathrm{C}$ \\
Operating temperature & $1 \mathrm{bar}$ \\
Operating pressure & $80 \%$ \\
Conversion effectiveness & $350^{\circ} \mathrm{C}$ \\
\hline Methanation Reactor & $1 \mathrm{bar}$ \\
\hline Operating Temperature & $27^{\circ} \mathrm{C}$ \\
Operating Pressure & $1 \mathrm{bar}$ \\
Inlet reactants Temperature & $1 / 4$ \\
Inlet reactants pressure & $20 \%$ \\
Molar Inlet fraction (CO2/H2) & \\
Molar Inlet fraction (CO/(CO2+CO)) & 7.75 \\
\hline SMIS & $80 \%$ \\
\hline Compression ratio (COMP1 \& COMP2) & $27^{\circ} \mathrm{C}$ \\
Isentropic Efficiency (COMP1 \& COMP2) & $27^{\circ} \mathrm{C}$ \\
Inter and after cooling temperature & \\
Intercooler outlet temperature (C1\&C2) &
\end{tabular}

The sweep air temperature and pressure remain at ambient conditions of $27^{\circ} \mathrm{C}$ and 1 bar. To enhance the overall efficiency of the complete process, a number of configurations are made for optimization. In all the configurations, attempt is made to achieve heat recovery from appropriate portions of the process for heating the feed water entering the inlet of SOEC. Configuration 'a' shown in Figure 4, indicates heat recovery from three sections of the process indicated as REC1, REC2 and REC3. First heat recovery comes at the sweep air cooling outlet that heats the water stream feeding the SOEC. Second heat recovery occurs at the Methanation reactor for further heating of the SOEC feed water stream. Finally the inlet feed water absorbs heat from the outlet stream of $\mathrm{H}_{2}$ stream coming out of the SOEC. Here vap1 and vap2 represent the vapor condition of the incoming stream of water fed to SOEC. SAB Feed 1 shows the stream of hydrogen gas coming from the SOEC which is mixed with the stream of incoming $\mathrm{CO}$ and $\mathrm{CO}_{2}$ in MIX3 and forms SAB Feed 2 before entering the Sabatier reactor. Syn1 is the output of Sabatier reactor which goes through 2 compression stages resulting in Syn 4. 


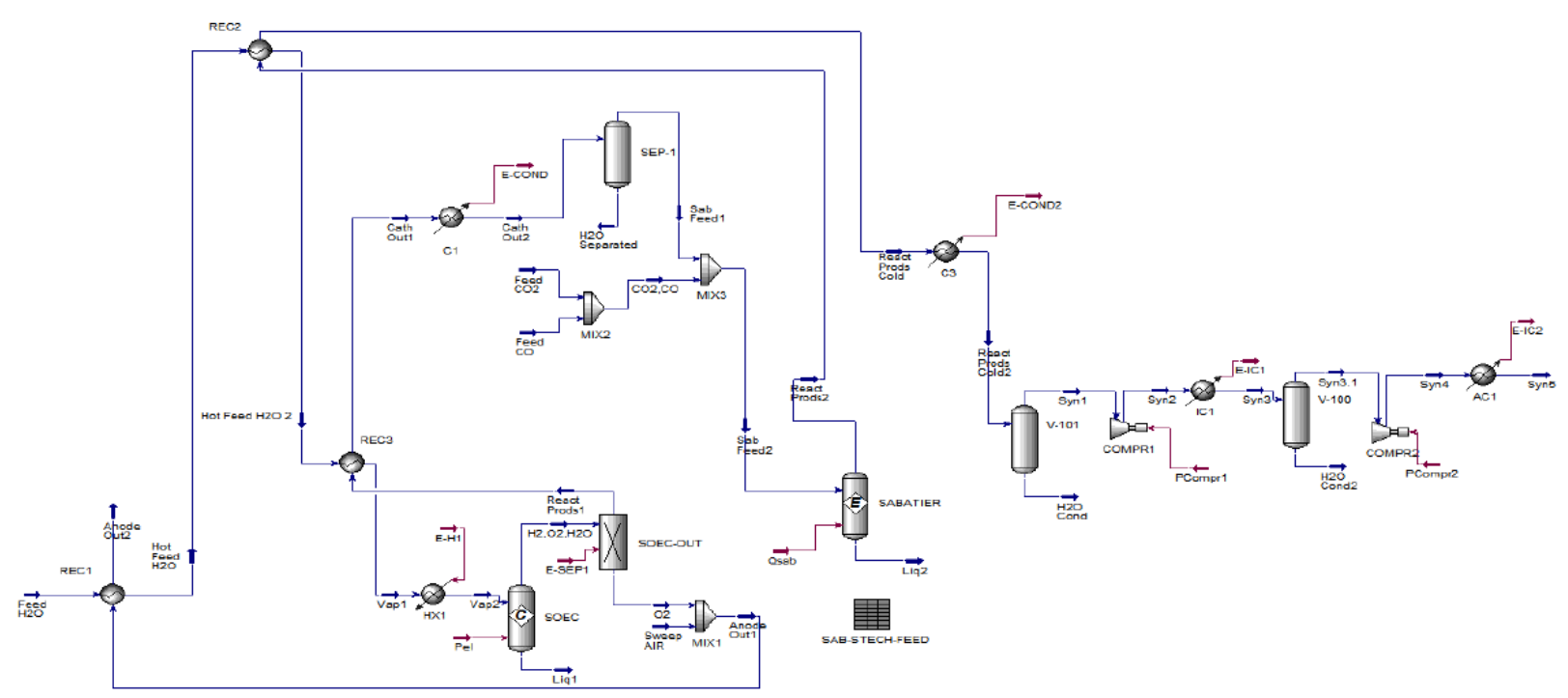

Figure 4. Configuration ' $a$ '

Configurations ' $b$ ' and 'c' are shown in Figures 5 and 6 respectively. In configuration 'b', the compression taking place after the Methanation reactor is placed before the reactor. Similarly configuration 'c' involves the compression taking place in two different stages, one prior to the methanation reaction and the second after the methanation process. In all the configurations, the reference parameters remain as per Table 1, however the assumptions made for each configuration are presented in Table 2.

For all the three recovery points in each of the three configurations, the Inlet temperature at the Methanation reactor remains at $27^{\circ} \mathrm{C}$. The temperature difference between the inlet cold side and the outlet hot side remain $5^{\circ} \mathrm{C}$ for each REC1, REC 2 and REC3. The isentropic efficiency is assumed to be $80 \%$ for all configurations.

Table 2. Parameters specific for different configurations

\begin{tabular}{|l|l|l|l|}
\hline Parameters & Configuration 'a' & Configuration ‘b' & Configuration 'c' \\
\hline $\begin{array}{l}\text { Inlet Methanation reactants } \\
\text { pressure }\end{array}$ & 1 bar & 60 bar & 30 bar \\
Compression ratio @ COMP1 & 7.5 & 7.5 & 5.5 \\
Compression ratio @ COMP2 & 7.5 & 7.5 & 5.5 \\
Compression ratio @ COMP3 & - & - & 2 \\
\hline
\end{tabular}

In order to evaluate the three configurations their performance is assessed in terms of the efficiency. The evaluating parameters are based on two indices; one is based on the conversion efficiency from electricityto-fuel and is estimated with the following relation:

$\eta_{\text {conv }, e 2 f}=\frac{\dot{\mathrm{m}}_{\text {syn }} * L H V_{\text {syn }}}{R_{e, R E T S}+R_{e, C O M P}}$

where

$\dot{\mathrm{m}}_{\text {syn }}=$ moles of $S N G$

$L H V_{\text {syn }}=$ Lower heating value of SNG

$R_{e, R E T s}=$ Electric power from the Renewable energy resources

$R_{e, \text { СомP }}=$ Electric power consumption in compressor .

Conversion efficiency defines the energy contained within the SNG produced as a result of the methanation reaction relating to the energy inflow to the system i.e. energy obtained from the renewable resources and the energy consumed by the compressor. 


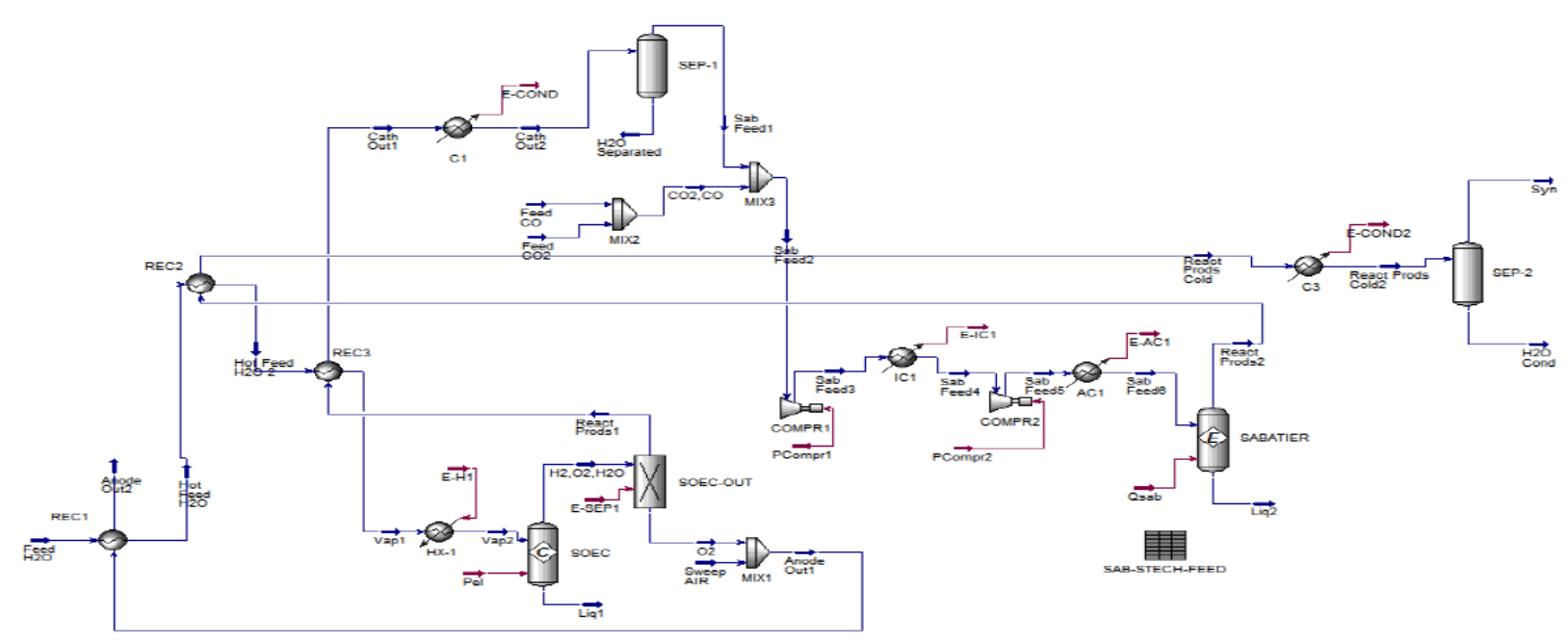

Figure 5. Configuration ' $b$ '

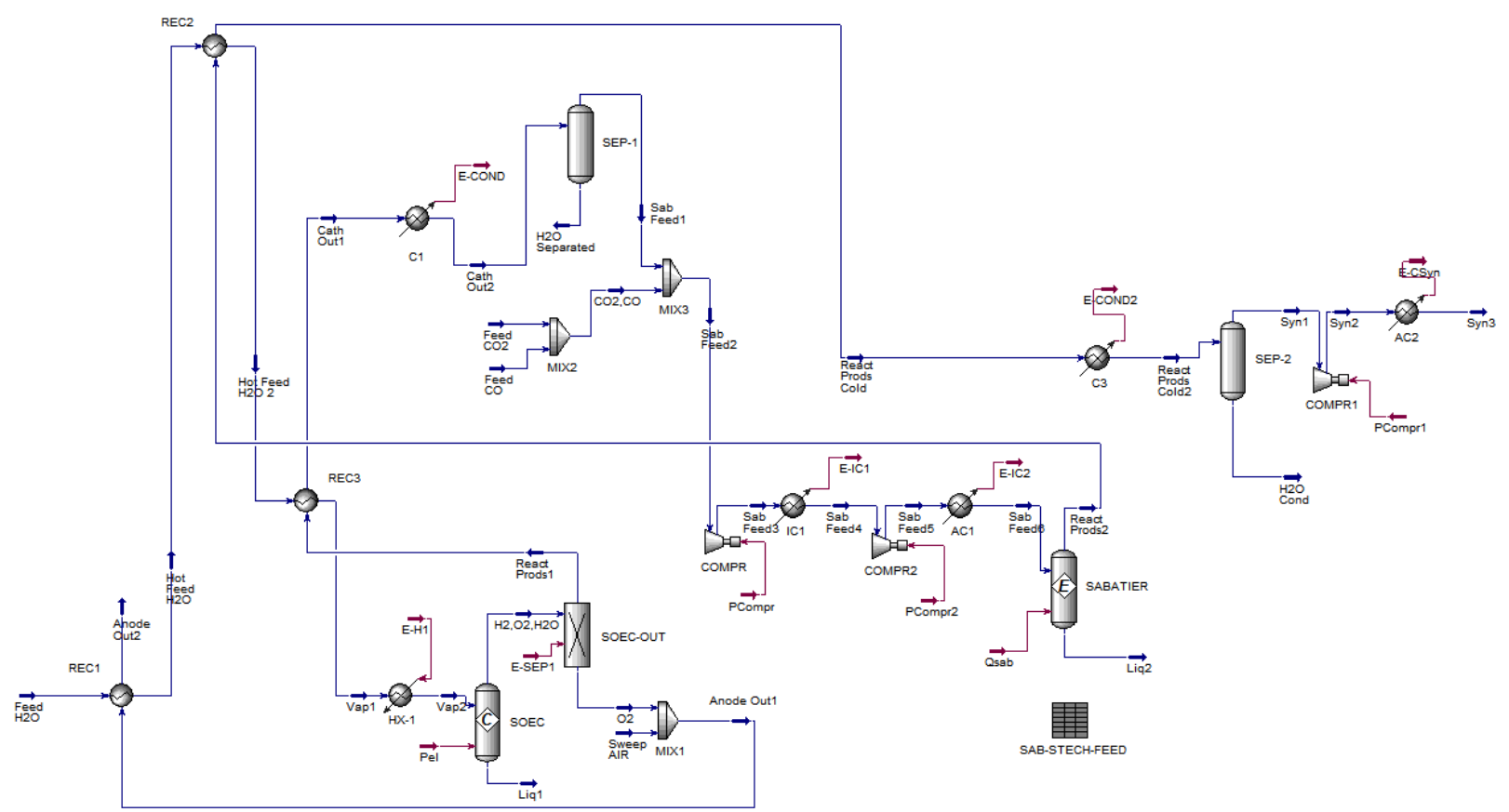

Figure 6. Configuration ' $c$ '

The conversion efficiency takes into account total heating value of the synthetic methane generated with respect to the electricity consumed by the SOEC and the compressors. In this case the heat recovery carried out at the three stages remains unaccounted. Therefore the conversion efficiency does not evaluate the correct efficiency of the P2G storage system. So as to draw an accurate analysis of the P2G system, it is necessary that the first law efficiency is also incorporated that caters for the total heat required and the total heat recovered

$$
\eta_{I, P 2 G}=\frac{\dot{\mathrm{m}}_{\text {syn }} * L H V_{s y n}}{R_{e, \text { RETs }}+R_{e, C O M P}+\sum Q_{t h, I N}-\sum Q_{t h, R e c}}
$$

where

$\sum Q_{t h, I N}$ is the required heat and $\sum Q_{t h, R e c}$ is the total heat recovery carried out from the different stages. 
Further, in order to ascertain the component with the lesser efficiency, individual performance of the different components viz. SOEC and the Methanation reactor is also evaluated with the following equations:

$$
\begin{aligned}
& \eta_{I, S O E C}=\frac{\dot{\mathrm{m}}_{\mathrm{H}_{2}} * L H V_{\mathrm{H}_{2}}}{R_{e, R E T S}+\sum_{S O E C} Q_{t h, I N}-\sum_{S O E C} Q_{t h, R e c}} \\
& \eta_{I, M R}=\frac{\dot{\mathrm{m}}_{\text {syn }} * L H V_{s y n}}{\dot{\mathrm{m}}_{\mathrm{H}_{2}} * L H V_{H_{2}}} .
\end{aligned}
$$

The comparison of the three configurations is further expanded to include the following parameters:

- Product composition: Synthetic methane gas produced in each of the three configurations is evaluated for its composition. The percentage of hydrogen in syngas for introduction into the natural gas infrastructures is limited from the point of view of inflammability.

- Product Quality: This parameter is defined by the Lower Heating Value of the product SNG.

- Wobbe Index: Wobbe Index determines the interchangeability of different fuel gases. In this case the index draws a comparison of the produced synthetic methane with respect to NG.

\section{FINDINGS AND RESULTS}

The results of the analysis are displayed in the form of Histograms in Figures 7-10.

\subsection{Electric-To-Fuel \& First Law - Efficiency}

Figure 7 depicts the results for the efficiency of the reference case as well as that for the different configurations. Maximum Electric-to-fuel conversion efficiency (85\%) is achieved for the Reference case and Configuration ' $a$ '. The lower efficiency for Configuration ' $b$ ' and ' $c$ ' is due to the additional compression work carried out at the SMIS. Although the overall compression ratio remains the same in all the configurations, the compression work in ' $b$ ' and ' $c$ ' is enhanced due to the change in position of the compression stages. The change in compression stages leads to a change in mass flow rate that increases the compressor work input.

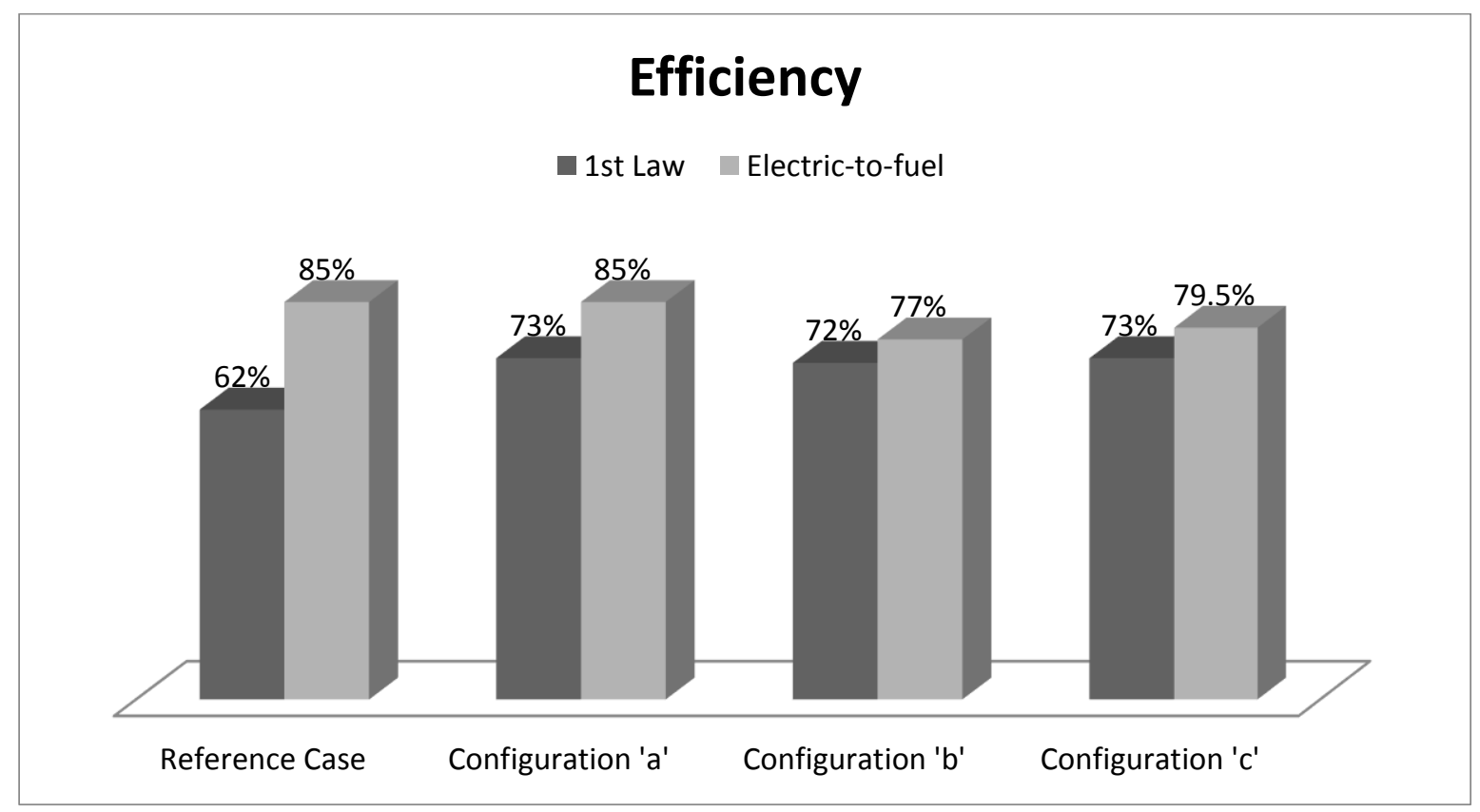

Figure 7. Efficiency of the Reference case Vs the Configurations 
First Law efficiency gets its highest value in Configurations ' $a$ ' and ' $c$ ' which is approximately $73 \%$. In any case it is higher from the Reference Case, for all configurations because of the fact that no heat recovery is taking place in Reference case.

\subsection{SOEC \& Methanation Reactor-Efficiency}

The 1st Law efficiency values for SOEC and MR as indicated in Figure 8 represent an opposing behavior for the two components. Higher efficiency of SOEC occurs at configuration ' $b$ ' and 'c', in contrast the higher efficiency values for MR is achieved in configurations in reference case and configuration ' $a$ '. In this regard configuration ' $a$ ' is the best option.

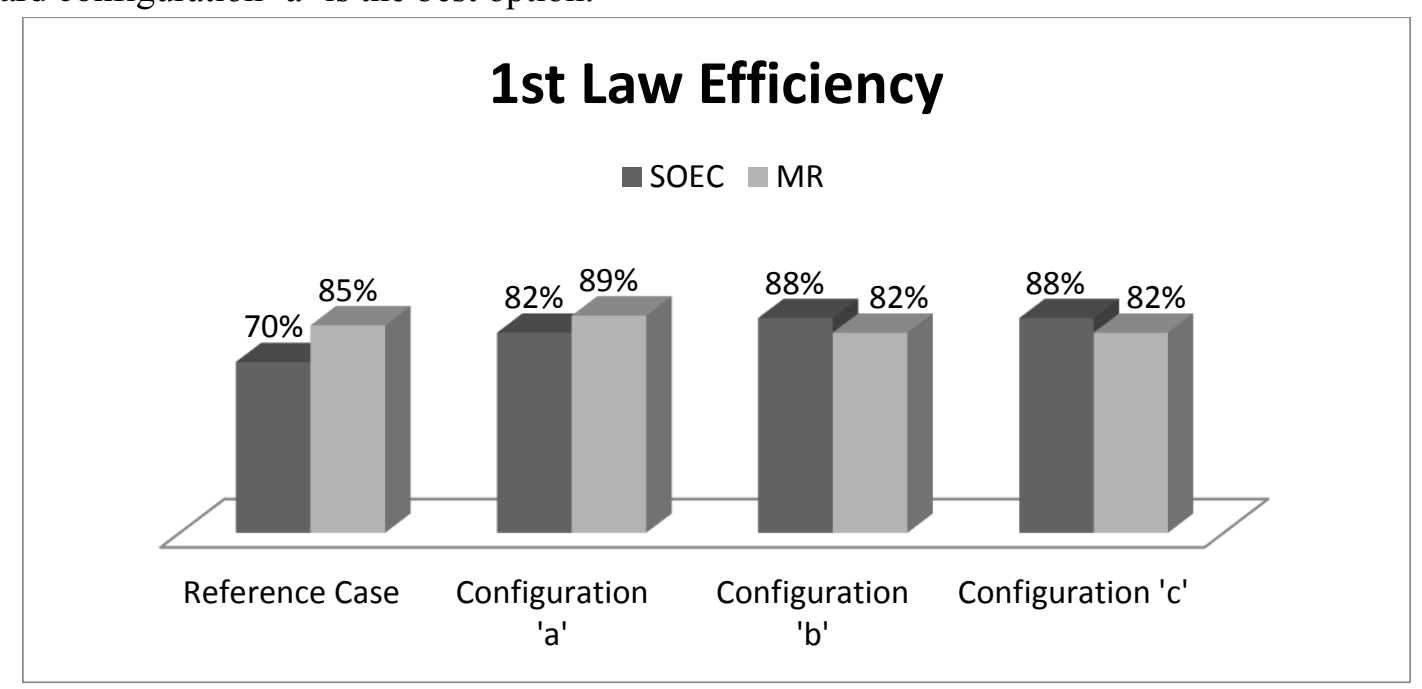

Figure 8. $1^{\text {st }}$ Law Efficiency for SOEC and MR

\subsection{Synthetic Gas Composition}

The product composition is one of the most significant aspects in determining the best possible configuration of the $\mathrm{P} 2 \mathrm{G}$ system. Apart from methane, the general composition of syngas contains a percentage of the initial reactants i.e. $\mathrm{H}_{2}$ and $\mathrm{CO}_{2}$.

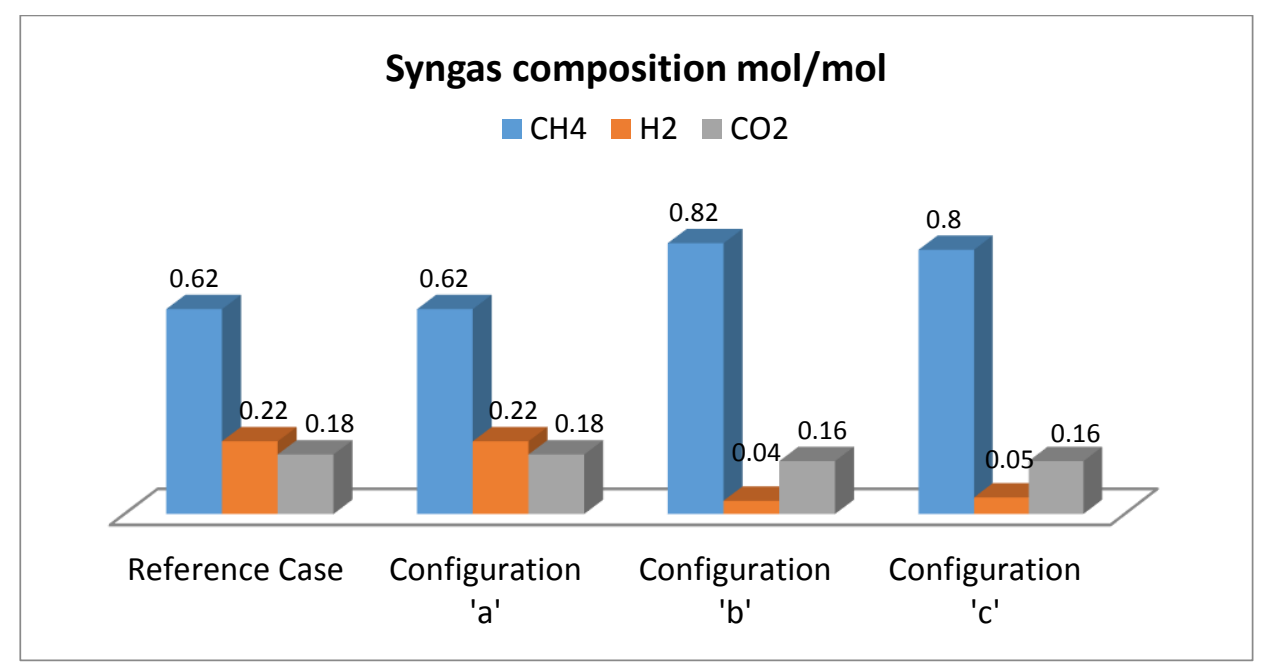

Figure 9. Syngas composition

Other products may include water and some traces of $\mathrm{O}_{2}, \mathrm{~N}_{2}$ and other oxides of carbon. In this evaluation only some water was found in the product stream while the remaining products were negligibly insignificant. Figure 9 presents the molar composition of methane to be highest in configurations ' $b$ ' and 
' $c$ ' attaining an $82 \%$ composition of methane in the product stream. In the same configurations, the presence of $\mathrm{H}_{2}$ is less than $5 \%$ and $\mathrm{CO}_{2}$ is also minimal which is a desirable aspect. It may be added here that configuration 'a' has been seen to give the highest conversion efficiency (Para 5.1), however the high content of hydrogen (>20\%) do not allow its injection into the NG infrastructure.

\subsection{LHV and Wobbe Index}

Figure 10 shows the values of LHV and Wobbe Index for the product stream. Configuration ' $b$ ' provides the best values of LHV $(34000 \mathrm{~kJ} / \mathrm{kg})$ and Wobbe Index $\left(40000 \mathrm{~kJ} / \mathrm{Nm}^{3}\right)$. These values when compared with the conversion and component efficiencies and methane composition suggest that configuration ' $b$ ' is the optimum model to be adopted for the P2G storage system.

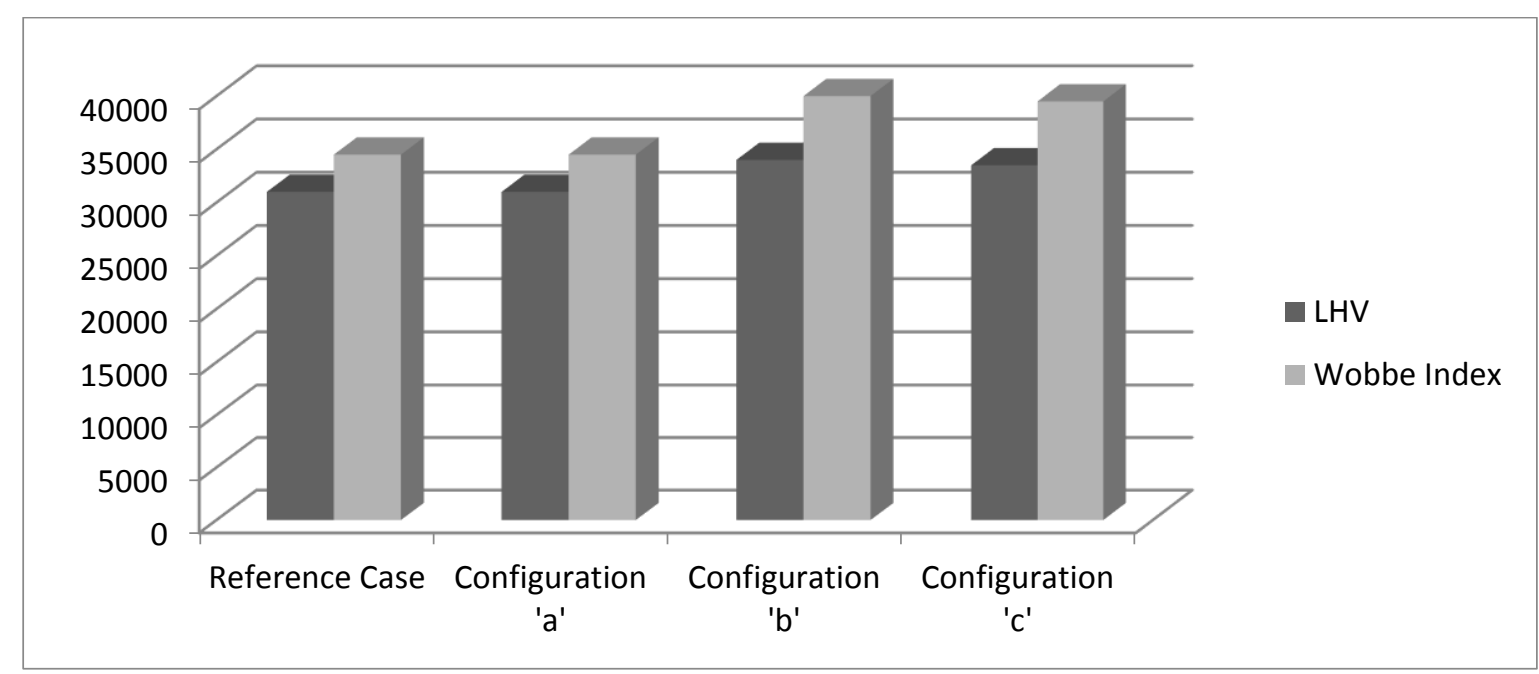

Figure 10. Syngas LHV $(\mathrm{kJ} / \mathrm{kg})$ \& Wobbe Index $\left(\mathrm{kJ} / \mathrm{Nm}^{3}\right)$

\section{CONCLUSIONS}

Solar, wind and biomass resources are available in considerable quantities in most areas of the world. Hydrogen and in turn synthetic methane is a good storage medium for these intermittent resources and is also advocated to be the prospective fuel for upcoming future and the most preferred energy vector in the medium-to-long range scenario. P2G systems help to integrate the energy grid and the renewable energy technologies.

The growing penetration of renewable energy resources in the market also requires that issues pertaining to power production and consumption are addressed in an effective manner. This study proposes the use of SOEC in the P2G storage system to achieve higher efficiencies. It has been recommended that further improvement in the efficiency of the process can be achieved through enhanced heat recovery and stagewise compression work. The optimum configuration results in higher efficiency, good product stream in terms of methane composition, and appropriate values for LHV and Wobbe Index.

The preheating of the feed water for the SOEC from three heat recovery stages has resulted in an increased efficiency. The Injection system comprising of compression stages has a marked effect on the percentage composition of methane in synthetic gas stream as well as the Wobbe Index and LHV. Keeping in view the sensitivities of all these parameters configuration ' $b$ ' presents the optimal solution.

\section{CONFLICTS OF INTEREST}

No conflict of interest was declared by the author. 


\section{REFERENCES}

[1] Dou, Y., Sun, L., Ren J., and Dong, L., "Opportunities and Future Challenges in Hydrogen Economy for Sustainable Development", Hydrogen Economy, pp. 277-305, (2017).

[2] Dickinson, R. R., Battye, D. L., Linton, V. M., \& Ashman, P. J., “Alternative carriers for remote renewable energy sources using existing CNG infrastructure", International Journal of Hydrogen Energy, 35(3): 1321-1329, (2010).

[3] Hashimoto, K., Habazaki, H., Yamasaki, M., Meguro, S., Sasaki, T., Katagiri, H., Matsui T., Fujimura K., Izumiya K., Kumagaid N., Akiyama, E., "Advanced materials for global carbon dioxide recycling", Materials Science and Engineering: A, 304: 88-96, (2001).

[4] Gao, J., Liu, Q., Gu, F., Liu, B., Zhong, Z., \& Su, F., "Recent advances in methanation catalysts for the production of synthetic natural gas", RSC Advances, 5(29): 22759-22776, (2015).

[5] Tabkhi, F., Azzaro-Pantel, C., Pibouleau, L., \& Domenech, S., "A mathematical framework for modelling and evaluating natural gas pipeline networks under hydrogen injection", International Journal of Hydrogen Energy, 33(21): 6222-6231, (2008).

[6] Haeseldonckx, D., "Concrete transition issues towards a fully-fledged use of hydrogen as an energy carrier”, KU Leuven, Heverlee, 108-121, (2009).

[7] Maroufmashat, A., \& Fowler, M., "Transition of future energy system infrastructure; through powerto-gas pathways", Energies, 10(8): 1089-1098, (2017).

[8] Gondal I.A., "Hydrogen integration in power-to-gas networks", International Journal of Hydrogen Energy, 44(3): 1803-15, (2019).

[9] Gondal, I.A., "Offshore renewable energy resources and their potential in a green hydrogen supply chain through power-to-gas", Sustainable Energy \& Fuels, 3(6):1468-89, (2019).

[10] Gondal, I.A., Masood, S.A., "Synergies in offshore wind and oil industry for carbon capture and utilization", Greenhouse Gases: Science and Technology, 9(5): 856-871, (2019).

[11] Jarvis, S M., Samsatli, S., "Technologies and infrastructures underpinning future $\mathrm{CO} 2$ value chains: A comprehensive review and comparative analysis", Renewable and Sustainable Energy Reviews, 85, 46-68, (2018).

[12] Carriveau, R., \& Ting, D. S. K., "Methane and hydrogen for energy storage (Vol. 2)", IET, 248-256, (2016).

[13] Saba, S.M., Müller, M., Robinius, R., \& Stolten, D., "The investment costs of electrolysis-a comparison of cost studies from the past 30 years", International Journal of Hydrogen Energy, 324$335,(2017)$.

[14] Götz, M., Jonathan, L., Mörs, F., Koch, A.M., Graf, F., Bajohr, S., Reimert, R., and Kolb, T., "Renewable Power-to-Gas: A technological and economic review", Renewable Energy, 85: 13711390, (2016).

[15] Hacker, B., Gesikiewicz, P. and Smolinka, T., "Arbeitspaket 1b: Systemoptimierung und Betriebsführung der PEM-Elektrolyse", Energie-Wasser-Praxis, 125-138, (2015). 
[16] Reytier, M., Iorio, S., Chatroux, A., Petitjean, M., Cren, J., Jean, M., Aicart, J., and Mougin, J., "Stack performances in high temperature steam electrolysis and co-electrolysis", International Journal of Hydrogen Energy, 40(35): 11370-11377, (2015).

[17] Jean, M., Baurens, P., and Bouallou, C., "Parametric study of an efficient renewable power-tosubstitute-natural-gas process including high-temperature steam electrolysis", International Journal of Hydrogen Energy, 39(30): 17024-17039, (2014).

[18] Giglio, E., Lanzini, A., Santarelli, M., and Leone, P., "Synthetic natural gas via integrated hightemperature electrolysis and methanation: Part I-Energy performance", Journal of Energy Storage, 1: 22-37, (2015).

[19] Götz, M., Jonathan, L., Mörs, F., Koch, A.M., Graf, F., Bajohr, S., Reimert, R., and Kolb, T., "Renewable Power-to-Gas: A technological and economic review", Renewable Energy, 85: 13711390, (2016).

[20] Schiebahn, S., Grube, T., Robinius, M., Tietze, V., Kumar, B. and Stolten, D., "Power to gas: Technological overview, systems analysis and economic assessment for a case study in Germany". International Journal of Hydrogen Energy, 40(12): 4285-4294, (2015).

[21] Bensmann, B., Hanke-Rauschenbach, R., Müller-Syring, G., Henel, M., and Sundmacher, K., "Optimal configuration and pressure levels of electrolyzer plants in context of power-to-gas applications", Applied Energy, 167: 107-124, (2016).

[22] Frontera, P., Macario, A., Ferraro, M., and Antonucci, P., "Supported catalysts for CO2 methanation: a review", Catalysts, 7(2): 59-67, (2017).

[23] Parra, D., and Martin K. P., "Techno-economic implications of the electrolyser technology and size for power-to-gas systems", International Journal of Hydrogen Energy, 41(6): 3748-3761, (2016).

[24] Kopp, M., Coleman, D., Stiller, C., Scheffer, K., Aichinger, J., and Scheppat, B., "Energiepark Mainz: Technical and economic analysis of the worldwide largest Power-to-Gas plant with PEM electrolysis", International Journal of Hydrogen Energy, 42(19): 13311-13320, (2017).

[25] Kötter, E., Schneider,L., Sehnke, F., Ohnmeiss, K., and Schröer, R., "Sensitivities of power-to-gas within an optimised energy system", Energy Procedia, 73 : 190-199, (2015).

[26] Jentsch, M., Trost, T., and Sterner, M., "Optimal use of power-to-gas energy storage systems in an 85\% renewable energy scenario", Energy Procedia, 46: 254-261, (2014).

[27] Bailera, M., Lisbona, P., and Romeo, L.M., "Power to gas-oxyfuel boiler hybrid systems", International Journal of Hydrogen Energy, 40(32): 10168-10175, (2015).

[28] Bailera, M., Lisbona, P., and Romeo, L.M., and Espatolero, S., "Power to gas-biomass oxycombustion hybrid system: energy integration and potential applications", Applied Energy, 167: 221-229, (2016).

[29] Gillessen, B., Heinrichs H. U., Stenzel, P., and Linssen, J., "Hybridization strategies of power-to-gas systems and battery storage using renewable energy", International Journal of Hydrogen Energy 42(19): 13554-13567, (2017). 
[30] Kezibri, N., and Bouallou, C., "Conceptual design and modelling of an industrial scale power to gasoxy-combustion power plant", International Journal of Hydrogen Energy, 42(30): 19411-19419, (2017).

[31] Bailera, M., Kezibri N., Romeo L.M., Espatolero S., Lisbona P., Bouallou C., "Future applications of hydrogen production and $\mathrm{CO} 2$ utilization for energy storage: Hybrid Power to GasOxycombustion power plants", International Journal of Hydrogen Energy, 42(19): 13625-13632, (2017).

[32] Gowtham, R., "Design and analysis of concrete building without insulation and with insulation using ANSYS 15 software", 212-220, (2019).

[33] ElGhazi, Y., Hamza, N., and Dade-Robertson, M., "Modelling and simulation of integrated responsive solar-shading with double skin facades in hot arid climates", 4th International Conference on Building Simulation and Optimization (BSO 2018), Newcastle University, 117-131, (2018).

[34] Nejat, P., Jomehzadeh F., Hussen H.M., Calautit J.K., and Abd Majid M.Z., "Application of wind as a renewable energy source for passive cooling through wind catchers integrated with wing walls", Energies, 11(10): 2536-2545, (2018).

[35] Lau, S., Zhao, Y., Lau, S. S. Y., Yuan, C., and Shabunko, V., "An investigation on ventilation of building-integrated photovoltaics system using numerical modeling", Journal of Solar Energy Engineering, 142-156, (2020). 